International Journal of Instruction e-ISSN: 1308-1470 • www.e-iji.net

Article submission code: 20200311115538

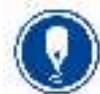

January $2021 \bullet$ Vol.14, No.1

p-ISSN: 1694-609X

pp. $927-946$

Received: 11/03/2020

Revision: 10/08/2020
Accepted: 01/09/2020

OnlineFirst: 05/12/2020

\title{
Corpus Pragmatics and Multimodality: Compiling an ad-hoc Multimodal Corpus for EFL Pragmatics Teaching
}

\section{Manuel Rodríguez Peñarroja}

Assoc. Lecturer, Universitat Jaume I, \& Universitat de València, Spain, penarroj@uji.es,manuel.rodriguez-penarroja@uv.es

The teaching and acquisition of foreign language pragmatics as a part of the communicative competence paradigm has been reported as essential since the deviation from the Chomskian competence-based model to a more performative one in the ' 80 s. Despite this change, only a few course books include or are designed on a teaching pragmatics basis. As an alternative, adapting and supplementing already existing course books with pragmatic content is the current trend. This paper takes a new look at materials design by merging pragmatics, corpus linguistics, and multimodality. The aim of this study is twofold: first, a specialized multimodal ad-hoc corpus was compiled in order to apply corpus pragmatics methodologies and search for multiple speech acts. Second, the development of an instructional model for the teaching of pragmatics in the English as a foreign language classroom is described. Thus, a specialised multimodal corpus from two TV series was compiled and edited using subtitles transcripts and the software Notepad++. Then, a quantitative and qualitative data analysis was performed through the use of AntConc freeware Clusters/n-grams and Concordance Plot tools. Results revealed the presence of multiple speech acts' direct, indirect and conventionalised realizations that allowed for the design of a teaching proposal that tackles both sociopragmatic and pragmalinguistic aspects.

Keywords: corpus pragmatics, EFL, multimodality, pedagogical proposal, pragmatics acquisition, speech acts, conversational aspects

\section{INTRODUCTION}

The acquisition of pragmatic competence has been reported as troublesome in the second and foreign language (SL and FL, henceforth) leaning contexts. Although instruction in pragmatics has been proved beneficial, course books' pragmatic input provision has been described as deficient due to its scarcity and inadequacy (BardoviHarlig, 2017; Tomlinson \& Masuhara, 2018). As a consequence, studies on the selfdevelopment of pragmatics teaching materials have been carried out so as to present

Citation: Peñarroja, M. R. (2021). Corpus Pragmatics and Multimodality: Compiling an ad-hoc Multimodal Corpus for EFL Pragmatics Teaching. International Journal of Instruction, 14(1), 927946. https://doi.org/10.29333/iji.2021.14155a 
learners with appropriate pragmatic input ${ }^{1}$. Course books are the main resources FL teachers' rely on; however, teachers tend to adapt, modify and take decisions on what parts or activities of the book should be implemented in class as "no course book can reasonably be expected to serve every context well" (Tatsuki, 2019 p.323). It is that tendency what calls for studies in which pragmatics is targeted and included in the SL and FL teaching and acquisition by means of adapting accessible pragmatic input and developing meaningful pragmatic tasks and activities. Tateyama (2019) reports on the need to cover pragmalinguistic and sociopragmatic information so as to provide students with a holistic perspective of the discipline itself.

In the age of linguistics' interdisciplinarity, this study aims at integrating pragmatics' principles and corpus linguistics methodologies with the objective of analysing TV genres' fictional discourse appropriateness as an input source for the teaching of pragmatics in the FL context. The significance of the present study for other researchers and language instructors relies on the description of how to compile and edit a specialised ad-hoc multimodal corpus using transcripts from TV fictional discourse. In addition, an account of the adoption of a corpus-based approach for the search and identification of Speech Acts (SAs) i.e. direct, indirect and conventionalised forms is given. Having provided evidence of SAs' presence in the corpus, the design of a teaching proposal with the objective of implementing pragmalinguistic and sociopragmatic language features in the EFL learning class is provided and discussed. Even the fact that the specialized ad-hoc corpus compilation and analysis entails the search of multiple SAs, both pragmalinguistic and sociopragmatic features are included in the instructional design as they are intrinsically related and necessary for a complete understanding of FL pragmatics. Thus, students will be exposed to complete audiovisual input from the corpus while completing tasks such as awareness-raising questionnaires, identification, and metapragmatic discussion.

This paper is organized as follows. Firstly, the literature review section gives a brief overview of corpus pragmatics emphasizing corpus linguistics methodologies' suitability when applied to teaching pragmatics. In addition, English as Foreign Language (EFL) learners' needs are described by outlining pragmatic competence as part of the overall language proficiency model stablished by the Common European Framework of Reference for languages (CEFR). Then, a revision of studies appraising for pragmatics teachability and the use of audiovisual material is also provided. The second section presents the analysis of a sitcom and drama TV series after the compilation of a specialized ad-hoc corpus in search of different speech acts (SAs) from previously developed taxonomies. The third section includes a proposal for the teaching of SAs and conversational aspects with the data obtained from the corpus. The last section includes some final remarks and future directions which may contribute to highlight the importance of providing FL learners with suitable pragmatic input so as to foster their pragmatic competence.

\footnotetext{
${ }^{1}$ For a recent review on materials development see Tatsuki (2019).
} 


\section{LITERATURE REVIEW}

\section{Corpus Pragmatics}

Pragmatics has been defined as "the study of language from the point of view of users, especially of the choices they make, the constraints they encounter in using language in social interaction and the effects their use of language has on other participants" (Crystal, 1997, p. 301). Thus, it implies knowledge and awareness of the linguistic and paralinguistic means available to convey meaning, on the one hand, and contextual factors, i.e. social context, specific conversational settings and politeness needs, which can constrain interaction, on the other (Taguchi, 2019). Such a functional perspective on language leads to the description of pragmalinguistics and sociopragmatics as the two main components of pragmatics which study the interrelationship between linguistic production and social and contextual needs (Barron, 2003; Brown \& Levinson, 1987; Martínez-Flor \& Usó-Juan, 2010). Pragmalinguistics makes reference to the linguistic resources available to convey illocutions, for instance Speech Acts (SAs), (in)directness and the different strategies to be accessed to when conveying meaning. Sociopragmatics is aimed at the description of how cultural, social, contextual, situational and interpersonal factors may influence interaction by sometimes limiting interactants' linguistic behaviour (Lo Castro, 2003).

Corpus linguistics has been described twofold, as an independent branch of linguistics or as a methodology for the study of language. Tognini-Bonelli $(2001$, p. 1) sees corpus linguistics as a discipline itself since it "goes well beyond this purely methodological role". Conversely, McEnery et al (2006, p. 8) suggest that corpus linguistics "should be considered as a methodology with a wide range of applications across many areas and theories of linguistics". Both perspectives highlight the usefulness and applicability of corpus linguistics to a number of areas in linguistics such as lexical studies, language variety, semantics and discourse analysis to mention some (Flowerdew \& Richardson, 2018). On the subject of the types of corpora, a distinction is made between general and specialized corpora (Römer, 2011). General corpora include large collections of texts, text types and genres consisting of different registers and language varieties which work as the ground for language and language varieties' general description and study, for instance, the COBUILD Bank of English (BoE), and the British National Corpus (BNC). Specialized corpora encompass particular compilations of texts described as domain, genre or setting specific. Their size is often small and these are compiled with specific research or teaching purposes which has been proved advantageous as more contextual information can be accessed (Campoy et al., 2010).

As regards the applicability of corpus data to the design of language teaching materials, there are four main corpora approaches: i) corpus-based is used to research previous linguistic theories "pre-corpus concepts" (McEnery et al., 2006, p. 10) from corpus data in order to validate, refuse, exemplify and develop these notions when "the theoretical statements are fully consistent with and reflect directly, the evidence provided by the corpus" (Tognini-Bonelli, 2001, p. 85), ii) corpus-driven linguists try to theorize about linguistic conceptions relying on data from the corpus itself with no pre-formulated linguistic assumptions, iii) the corpus-informed approach benefits from corpus data "in the construction of a syllabus, including the selection not only of grammar and 
vocabulary, but also topics and methodology" (Furniss, 2016, p. 134), iv) the corpusreferred approach explicitly allows for "intuition, experience, local need, cultural appropriacy and pedagogic convenience in determining syllabus content and the order in which items are taught" (Timmis, 2013, p. 470). Any of the previous approaches taken as the starting point, Römer (2011) reports on the need to examine learners needs i.e. evaluating students' FL proficiency level and analysing their communication needs and learning difficulties.

Having described both disciplines separately, corpus pragmatics can be understood as the alliance of pragmatics and corpus linguistics' methodologies which main aim is to integrate corpus linguistics vertical search and pragmatics' horizontal analysis (Rülhemann \& Aijmer, 2016). This association aims to study previously established pragmatic phenomena while it allows for wider context analysis using corpus linguistics tools and adopting a form-to-function approach. Corpus pragmatics' usefulness resides in the possibility of using corpus linguistics methodologies and computer-aided searches for the study of pragmatic phenomena may these imply form-function mismatch and need wider utterance context to be interpreted. For example, the identification and study of indirect SAs as these are not usually conveyed in a fixed or conventionalized linguistic form and require line-by-line reading (McAllister, 2015). Furniss (2016) designed a corpus-based website for the teaching of nine routine formulas in Russian. The corpus consists of transcripts from twenty-one Russian films with a total of 89,357 word tokens. FL students were exposed to nine routine formulas, which were representatively present in the corpus while completing a series of online instructional modules. After instruction, students completed a feedback form on the instruction they received and were interviewed by the researcher. Results from this interventional study reported students' increased awareness of the routine formulas since form-functioncontext mappings were strengthened by means of the activities in the modules and exposure to audiovisual input from films. In line with Furniss (2016), the present study has required the compilation of a specialized ad-hoc corpus from the transcripts of two TV series. Then, corpus-based computerized searches and line-by-line reading for SAs identification have served to identify SAs lexical items and phrases. Once identified in the corpus, these have been used in the teaching proposal so as to exemplify SAs realization and provide students with contextualized conversations through audiovisual input. The question that may arise is whether pragmatics acquisition is a feasible goal for EFF students.

\section{Pragmatics Instruction}

As described in the most recent revision and update of the CEFR, overall language proficiency is seen as a set of strategies and competences to be mastered by language learners. Pragmatics is described as a communicative language competence aimed at the proper use of linguistic and non-linguistic resources, i.e. pragmalinguistics, in a number of contexts and specific situations, i.e. sociopragmatics. In order to assess pragmatic competence, the CEFR (2018, pp. 138-144) stablishes some parameters to be mastered at each proficiency level. A general description includes i) flexibility which makes reference to the adaptation of language production according to different circumstances; ii) turntaking implies speakers attachment to the dynamics of interaction; iii) thematic 
development entails the production of clear arguments by expanding and supporting points of view; iv) coherence and cohesion require the production of a coherent whole of separate elements by the use of cohesive resources; v) propositional precision refers to the expression of ideas as regards the setting and disambiguation; and vi) spoken fluency is described as the ability to produce utterances, keep the conversational flow going and ease of speech production. Of crucial importance for this paper, the CEFR new descriptors (2018) include audiovisual reception activities and strategies such as watching TV and films. At different proficiency levels, learners may be able to follow interactions, identify topic changes, implied meaning and idiomatic language use amongst others. Hence, exposing students to multimodal pragmatic input may help them notice and increase their awareness of the parameters stablished by the CEFR if compared to conventional presentation of decontextualized dialogues as appear in most EFL course books.

In the literature, studies have shown positive evidence for the teaching and acquisition of pragmatic aspects being SAs, interactional patterns and politeness needs the most widely researched. As pointed out in Alcón \& Martínez-Flor (2008), pragmatic aspects' teachability has been carried out examining suggestions (Martínez-Flor \& Alcón, 2007), apologies (Olshtain \& Cohen, 1990), compliments and compliment responses (Rose \& $\mathrm{Ng}$ Kwai-fun, 2001), requests (Martínez-Flor, 2007); pragmatic fluency (House, 1996), and discourse competence (Alcón, 1997). Martínez-Flor and Alcón's (2007) objective was to determine the differences between implicit and explicit teaching conditions in students' pragmatic awareness of the SA of suggestions. The study followed a pre and post-test design and EFL participants were divided into three groups: group A instruction consisted of metapragmatic account on suggestions, awareness-raising and production tasks; group B students were exposed to input enhancement and recast techniques, and group $\mathrm{C}$ (control group) received no instruction at all. After the instructional period, group A and B participants were able to identify inappropriate suggestions and provide more suitable alternatives as required by the conversational context. Thus, pragmatic instruction revealed overall positive results in both groups leading them to affirm that instruction in pragmatic aspects had a positive effect on learners' pragmatic competence.

Even the fact that these studies have suggested positive results when students receive pragmatics instruction, there is the common claim that EFL students' main difficulty resides in the accessibility to pragmatic input as it has been proved to be scarce (Tomlinson \& Masuhara, 2018). The main input sources students rely on, those of EFLdesigned course books, teacher talk, and other learners have been widely criticized as they lack appropriate pragmatic input provision and metapragmatic reflection (Abrams, 2014; Tatsuki, 2019). In an attempt to solve this problem, the usefulness of wellselected audiovisual input for the teaching of pragmatic aspects has been fostered as it can provide students with: i) contextualized pragmatic aspects; ii) aural and visual stimuli; iii) conversations within complete communicative situations and specific purposes; iv) interactants in real life situations; v) a wide range of SAs; vi) interaction dynamics elements such as intonation, turn-taking processes, sequences, and body language; and vii) target culture information (Tognozzi, 2010; Washburn, 2001). 
Accordingly, multimodal pragmatic input provision may aid students' access to meaningful and complete information to be examined and processed.

Moradkhan and Jalayer (2010) study was aimed at determining the effects of exposure to only aural input from podcasts, and aural and visual input from the TV series Friends and Desperate Housewives. EFL participants were divided into two groups, one exposed to aural input and the other to aural and visual input. Both groups received similar instruction which included a pre-viewing/listening activity which was aimed at activating students' background knowledge while introducing them to formality and informality and how these can be achieved when making a request, suggestion, giving advice and complaining in different contexts. Then a viewing activity in which students were shown video/audio fragments focusing their attention on characters' directness and indirectness when speaking. Last, the post-viewing/listening activity made students relate direct and indirect SA production with characters degree of familiarity and the context in which the conversation was taking place. Results revealed that the group exposed to complete audiovisual input outperformed the aural input one as regards pragmatic awareness development and overall EFL pragmatic competence.

\section{Audiovisual pragmatic input provision: multimodal corpora}

Some scholars have appraised for the design and use of multimodal corpora so as to build a bridge between the study of pragmatic phenomena, audiovisual input use and the corpus-based approach. Multimodality has been originally defined as a research area that centres attention to the non-verbal communicative resources and their relationship with meaning construction in interaction (Camiciottoli \& Campoy-Cubillo, 2018). It "can be understood as a theory, a perspective or a field of enquiry or a methodology" (Jewitt, 2009, p. 12). Centering attention to the pedagogical applications of multimodality, two important aspects have been highlighted. First, it addresses the effect of non-verbal elements such as gestures and body language as facilitating comprehension, while the second undertakes learner motivation (Shih, 2014) in light of a new generation of students born in the digital-media age who are exposed to "multisemiotic digital input" (Camiciottoli \& Campoy-Cubillo, 2018, p. 1) from Subscription Video On Demand (SVOD) such as Amazon, HBO and Netflix (Wayne, 2018). Thus, the provision of pragmatic input through multimodal corpora may aid comprehension as written corpus excerpts might lack the background information to widely understand and interpret pragmatic meaning in different communicative situations. Adolphs (2008) recommends the development of multimodal corpora, i.e. video and audio recordings, since relying on written transcripts may not allow for studying larger contextual cues, nor immediate ones that reflect the dynamics of interaction as shaping interactants' communicative objectives. Similarly, Ishihara \& Cohen (2010) acknowledge the provision of context and participants' information as crucial for the design of corpus-based teaching pragmatics materials, since these can lead to a wider understanding of the communicative situations and boost awareness. Bonsignori (2018) compiled a multimodal corpus on an English for Specific Purposes (ESP) teaching basis. The multimodal corpus consists of clips related to politics, economics, law, medicine and tourism and is aimed at studying the effects of multimodal input provision on language and culture learning. The author concludes that 
students may benefit from exposure to English native speakers' accents, the possibility of viewing language used in specialised contexts, and meaning making by having access to non-verbal and paralinguistic information. Importance is also given to the different activities and skills-practice that this type of corpus allows for.

Thus, given i) EFL students need to be instructed in pragmatics as stablished by the CEFR, ii) the positive results of previous research in the teaching of diverse pragmatic aspects, and iii) the impact of audiovisual materials on pragmatic and metapragmatic awareness, the following section is devoted to the description of a case study through which a multimodal corpus is compiled for its later implementation in a pragmatics teaching proposal.

\section{CASE STUDY: MULTIPLE SAs IN TV SERIES}

The first part of this study is aimed at the compilation of a multimodal specialized adhoc corpus from the first season of the TV series Life on Mars and How not to live your life for a posterior search and identification of SAs. These sources have been selected due to episode length (from 25 to $50 \mathrm{~min}$ on average), characters typology (usually recurrent and familiar characters), contextual factors (everyday situations), and circular structure (problem-resolution-ending). To that aim, we have searched for multiple SAs from previously developed taxonomies with AntConc (Anthony, 2019) freeware tools in order to verify that the SAs in fictional dialogue from both TV genres follow the SAs' types and strategies previously suggested by researchers' taxonomies. The identification of SAs granted the collection of fully contextualized conversations from the series that served as multimodal pragmatic input to be implemented in the teaching proposal.

\section{METHOD}

The specialized corpus has a total of 64,965 word tokens and the SAs searched include apologies, complaints, refusals, requests and suggestions ${ }^{2}$. The SAs taxonomies differentiate into direct, indirect, and conventionalized forms, and include the linguistic strategies to perform the speech acts and some paradigmatic examples. The first part of the process entailed the adaptation of the linguistic production as present in the original subtitles (.srt file) into a script-like format (txt.file) by completing and editing characters' linguistic production using Notepad ++ software.

\begin{tabular}{ll}
\hline Raw linguistic production (.srt) file & Edited linguistic production. \\
\hline 513 & Gene: Do you know who she works for? \\
00:33:08,671 --> 00:33:10,791 & Sam: What? \\
$\begin{array}{l}\text { Do you know } \\
\text { who she works for? }\end{array}$ & Gene: The girl. Do you know who she works for? \\
514 & Sam: Yeah. But that's why she came to see me. \\
& \\
\hline
\end{tabular}

Figure 1

Linguistic content edition

\footnotetext{
2 The SAs searched are based on the taxonomies developed by Martínez-Flor (2005) suggestions; (Chang, 2010; Kondoh, 2010) apologies; (Boxer, 2010; DeCapua, 1998; Murphy \& Neu, 1996; Olshtain \& Weinbach's, 1988; Trosborg, 1995) complaints; (Salazar, Safont and Codina, 2009) refusals; (Trosborg, 1995 in Usó-Juan, 2010: 205) requests.
} 
The linguistic production of the characters as seen on the screen and after edition is presented above in Figure 1. On the left, the (.str) file raw content with the number of the subtitle, the time sequence and the text as appearing on the screen are shown. On the right, the edited text in a script-like format is presented with the name of the characters and their linguistic production. Once the text was compiled, the second step was devoted to the search and identification of direct and conventionalized SAs' strategies as present in the taxonomies. To that aim, AntConc freeware (Anthony, 2019), in particular, Clusters/n-grams lists of SA types from one to five words were compiled. Then, Concordance Plot tools were used to confirm whether the different direct and conventionalised strategies for the SAs searched were present in the corpus. Then, File View, Concordance tools and reviewing audiovisual fragments allowed the researcher to confirm that the illocutionary force (i.e. words intentionality) of the pragmalinguistic forms (i.e. SA production) matched SAs' direct and conventionalized strategies. As reported in McAllister (2015), reading the scripts while watching the episodes repeatedly has been necessary so as to identify indirect SAs' strategies. Results are presented below under a mixed methods approach (Ross \& Hong, 2019) integrating quantitative results and their qualitative interpretation in order to exemplify SAs types and the most representative strategies as found in the corpus.

\section{Quantitative and qualitative results}

Results from the SAs' types as found in the sitcom and drama audiovisual genres researched are presented quantitatively and qualitatively by providing their raw count, percentage and examples with the most widely used strategies in bold.

Table 1

Quantitative results.

\begin{tabular}{|c|c|c|c|}
\hline SA type & & Raw count & $\%$ \\
\hline \multicolumn{4}{|c|}{ Apologies } \\
\hline & Direct & 57 & $56 \%$ \\
\hline & Adjunct & 45 & $44 \%$ \\
\hline Total & & 102 & $100 \%$ \\
\hline \multicolumn{4}{|c|}{ Complaints } \\
\hline & Direct & 72 & $74 \%$ \\
\hline & Indirect & 25 & $26 \%$ \\
\hline Total & & 97 & $100 \%$ \\
\hline \multicolumn{4}{|l|}{ Refusals } \\
\hline & Direct & 46 & $41 \%$ \\
\hline & Indirect & 65 & $59 \%$ \\
\hline Total & & 111 & $100 \%$ \\
\hline \multicolumn{4}{|c|}{ Requests } \\
\hline & Direct & 57 & $39 \%$ \\
\hline & Conventionally indirect (hearer-based) & 36 & $25 \%$ \\
\hline & Conventionally indirect (speaker-based) & 42 & $29 \%$ \\
\hline & Indirect & 10 & $7 \%$ \\
\hline Total & & 145 & $100 \%$ \\
\hline \multicolumn{4}{|c|}{ Suggestions } \\
\hline & Direct & 14 & $13 \%$ \\
\hline & Conventionalized forms & 71 & $67 \%$ \\
\hline & Indirect & 21 & $20 \%$ \\
\hline Total & & 106 & $100 \%$ \\
\hline
\end{tabular}


The SAs' searched and the main strategies found in the scripts from the sitcom and the drama TV series are displayed above in table 1. As regards apologies, a similar number of direct $(56 \%)$ and adjunct $(44 \%)$ strategies were found. The most frequently used direct strategy is expression of regret: "Sorry, what did I say?" while expression or account for the situation: "oh, oh well, when there was no answer, I just used my keys" was found as the most common adjunct strategy. Results from the SA of complaining revealed that indirect complaints $(26 \%)$ were almost twice less frequent than direct ones $(74 \%)$. The most salient direct strategies are expression of annoyance/disapproval: "Well seeing as you're too rode to offer, I thought I'd go and make myself a cup of tea", and explicit complaints: "You're upsetting him!" both addressing the hearer in a direct way. Direct $(41 \%)$ and indirect $(59 \%)$ refusals were found quite balanced. Negation of the proposition: "I can't, I don't think so, I do not need help, Eddie" is a highly recurrent direct strategy. Indirectness is achieved through providing an explanation or reason: "Eddie. I've not got a costume". The SA of requesting types include direct requests (39\%) accomplished by the use of imperatives: "Give us me clothes, a brew and a bun", conventionally indirect (hearer-based) requests (25\%): "Well, can I at least get a letter of recommendation?"; conventionally indirect (speaker-based) (29\%) which mainly stands for speaker expression of wishes, desires and needs; and indirect requests $(7 \%)$ are mostly hints which lead the illocutionary force of the request to hearer's interpretation: "You don't mind showing Karl where to put my stuff, do you?". The strategies used for conveying suggestions are direct (14\%) which corresponds to the use of performative verbs such as suggest, advice and recommend: "The way this is sprayed suggests an attack carried out at speed"; conventionalized forms are mainly achieved with the use of the modal verb should and specific formulae: "why don't we do this later?". Indirect suggestions are conveyed using impersonal strategies: "there's some underage drinkers here".

After the edition, analysis, identification and classification of multiple SAs' strategies, results on a script-like format including SAs types and the strategy were developed. Figure 2 below presents the final outcome of the analysis by providing the SAs identified, the strategies used, conversational sequences and the turn-taking processes in conversation.

(...)

Abby: So, what happened to the actual television?

Eddie: Oh, the bailiff took it.

Don: It's not funny, Menford. That TV was like a brother to me. (Ind. Complaint:

Situation directed) Why does everything I love leave me?

Abby: Karl, you were thinking of buying me a new television, weren't you? (Ind.

Suggestion)

Karl: I was?

Abby: Maybe now's the time. (Ind. Suggestion: Hint)

Eddie: Er, Don?

(...)

Figure 2

SAs tagged in a sample conversation. 
Thus, in consonance with previous studies conducted on different SAs' presence in fictional dialogue and the usefulness of using TV genres for EFL teaching (Alcón \& Guzmán-Pitarch, 2010; Bonsignori, 2018; Fernández-Guerra, 2008; Rose, 2001; Tatsuki \& Kite, 2006; Martínez-Flor, 2007), results from the analysis also support the presence of most SAs' pragmalinguistic strategies in the sitcom and the drama TV series, which tend to represent everyday language use. Findings allowed the researcher to compile different TV series scenes including multiple SAs in a multimodal corpus of audiovisual scenes which were later used as a source of pragmatic input to expose students to complete contextualised conversations.

\section{A TEACHING PRAGMATICS PROPOSAL IN THE EFL CLASSROOM}

Having provided evidence of the SAs in the audiovisual genres, this section aims to describe an instructional model for the teaching of pragmatics i.e. pragmalinguistic resources and sociopragmatic aspects, in the EFL classroom. As regards instructional models and corpus linguistics methodologies, McEnery et al. (2006) describe the traditional top-down deductive 'three Ps' approach (presentation-practice-production) as not suitable enough for the application of corpus linguistics methodologies. Instead they suggest the bottom-up inductive 'three Is' approach (illustration-interaction-induction) through which learners become researchers. Illustration stands for observing real data; interaction requires the metacommunicative practices which entail the discussion and sharing of ideas from the previous observation; induction implies rules development based on observation and interaction. Both approaches may provide the learner with valuable linguistic information from corpus when applied to language teaching. Nevertheless, explicit instruction has been reported as more effective than implicit. In a revision of studies assessing SL/FL pragmatics learnability, Takahashi (2010) advocated for the benefits of explicit instruction and the provision of metapragmatic information since pragmatics acquisition requires attention, awareness and noticing (Abrams, 2014; Taguchi \& Roever, 2017). Correspondingly, Ishihara and Cohen (2010) contend that explicit instruction is necessary in FL contexts meanwhile implicit instruction may suit better SL contexts in which students have wider access to the target language.

Following this last assumption, the present proposal of an instructional model for intermediate adult EFL learners' pragmatics acquisition advocates for i) an explicitdeductive type of instruction as proved effective when teaching pragmatic aspects (Weinert, 2009); ii) metapragmatic information provision and discussion (Glaser, 2013); iii) a focus on forms (FonFormS) approach (Ellis, 2002); iv) exposure to multimodal input (Bonsignori, 2018); and v) the use of identification tasks and awareness-raising questionnaires (Abrams, 2014) as suggested in Ishihara and Cohen (2010).

\section{$1^{\text {ST }}$ Step: Audiovisual input and sociopragmatics}

The first step entails explicit instruction in pragmatics and its components as well as the description of the audiovisual TV series that students will be exposed to. A short definition of pragmatics will be first presented. Then, sociopragmatics and pragmalinguistics will be briefly outlined. The former encompasses the description of the sociological variables of power, distance and imposition (Brown \& Levinson, 1987), participants and context, while the latter includes the description of conversation, turn- 
taking processes, adjacency pairs, sequences, and the SAs types and strategies researched. This first stage is aimed at directing students' attention to the input they are going to work with and the metapragmatic information they will be provided so as to promote noticing and awareness which may lead to acquisition (Schmidt, 2012). Simultaneously, awareness-raising tasks such as sociopragmatic questionnaires designed on corpus-evidence basis have to be gradually overcome. A sample of three sociopragmatic tasks is provided below.

Task 1. Imagine yourself in a conversation. What factors can influence that particular interaction?

$$
\text { 1. Who are you talking to? }
$$

Boss/employee; professor/student; citizen/authority.

2. Relationship with the other person.

Unknown people; friends; friends of friends; class/workmates; boss; close friends; family.

3. Speaker(s) purpose when communicating.

Ask for a favour/information/forgiveness/an explanation; complain; sharing experiences; apologise.

4. Where the conversation takes place

Class, workplace, office, home, bar, pub, street.

5. Participants:

Feelings, impression/image they want to give; attitude; mood; personality; body language; behaviour.

\section{Figure 3}

Task 1, warm-up sociopragmatic questionnaire.

The warm up questionnaire above is aimed at raising general awareness of the sociological variables (items 1-3), conversational context (item 4) and the participants involved (item 5) by reflecting on students' daily interactions. The objective is to promote metapragmatic awareness and metapragmatic in-class discussion. The teacher may act as a moderator and guide the discussion by providing extra information and examples to make students notice how these factors can influence their everyday interactions.

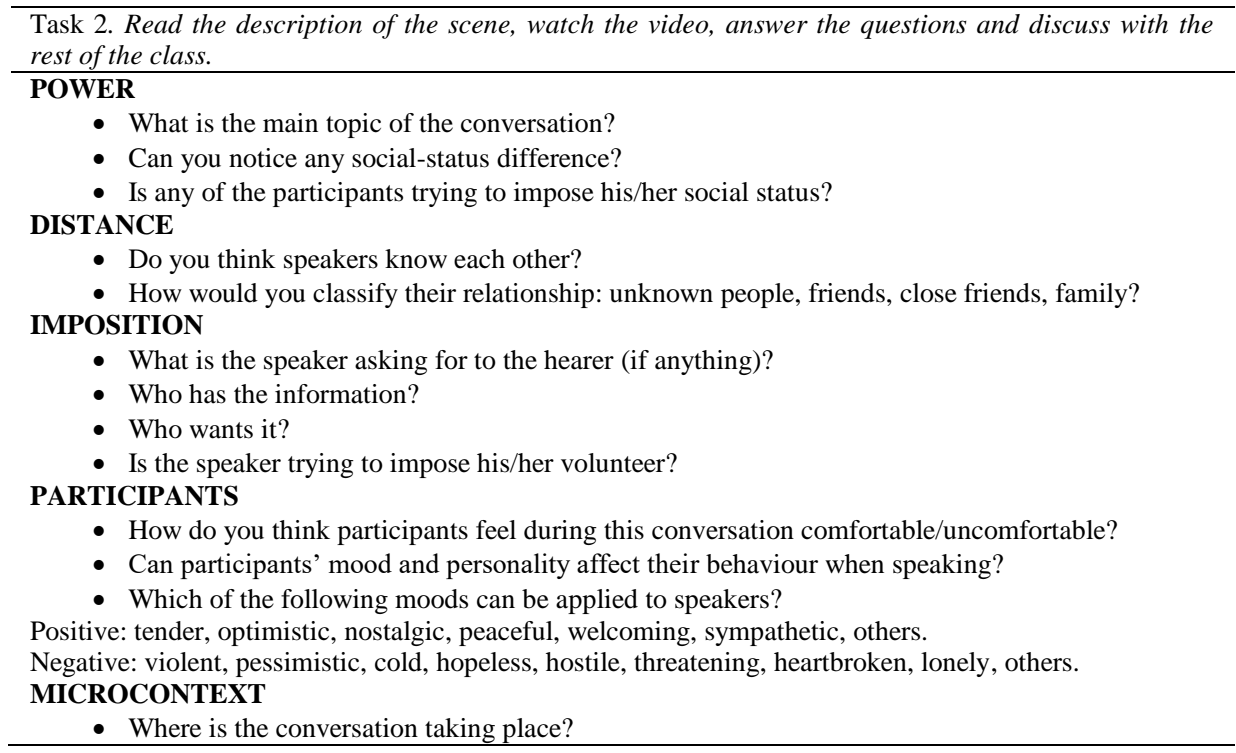




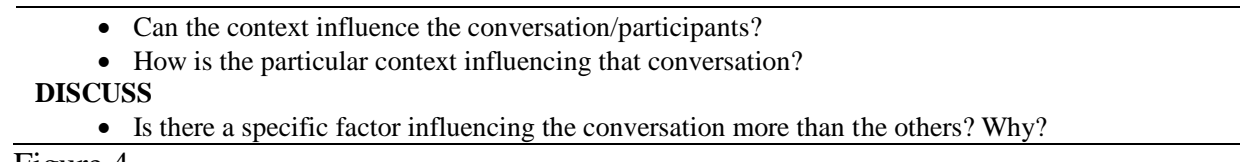
Figure 4

Task 2, audiovisual sociopragmatic questionnaire.

Above, a more specific sociopragmatic awareness-raising questionnaire to be carried out after watching a TV series scene is presented. Leaners' have to read a short description of the scene they are going to watch and answer the questions while discussing with the rest of the class. At the same time, they are being exposed to multimodal input and metapragmatic information, i.e. the concepts of power, distance, imposition, participants and context in a more explicit way than in the previous warm-up questionnaire. It is the teacher role to provide guidance throughout the discussion and raise students' awareness of these aspects' interrelationship as affecting interaction.

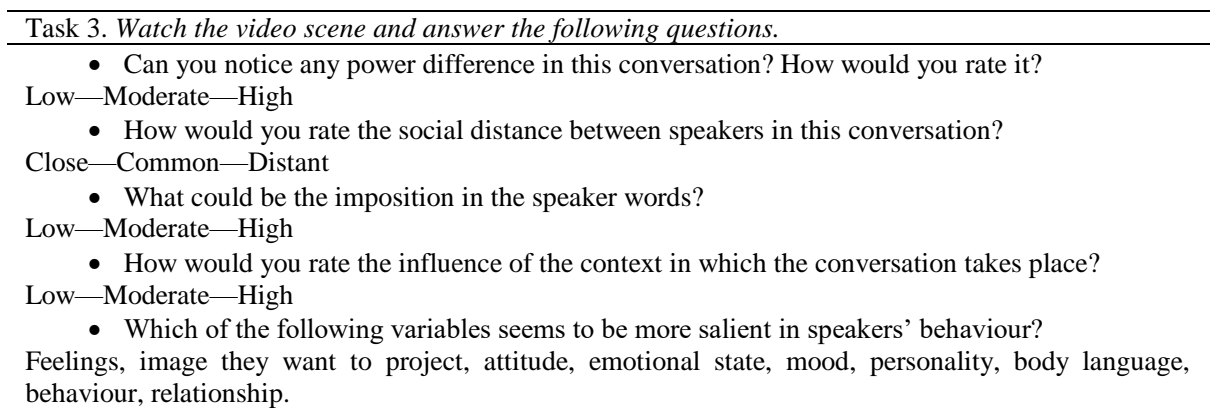
Figure 5

Task 3, sociopragmatic assessment questionnaire.

The last step involves the overcoming of a multiple-choice assessment questionnaire after watching a series scene. This task entails students' evaluation of the sociopragmatic factors previously explained and practiced by means of rating the different sociopragmatic items in the interaction. Individually, students read a short description of the situation they are going to watch. The main aim when completing the questionnaire is to show their awareness on sociopragmatic aspects and their possible effects in interaction. The teacher may foster students' awareness by providing the most suitable answers and generate in class metapragmatic discussion by means of awarenessraising questions.

\section{$2^{\mathrm{ND}}$ Step: Pragmalinguistics}

Throughout the second step, students are explicitly instructed on the conversational aspects of SA, turn, turn-taking process, sequences, and the SAs as found in the taxonomies by means of identification tasks while watching audiovisual fragments. Two task samples are provided below. 


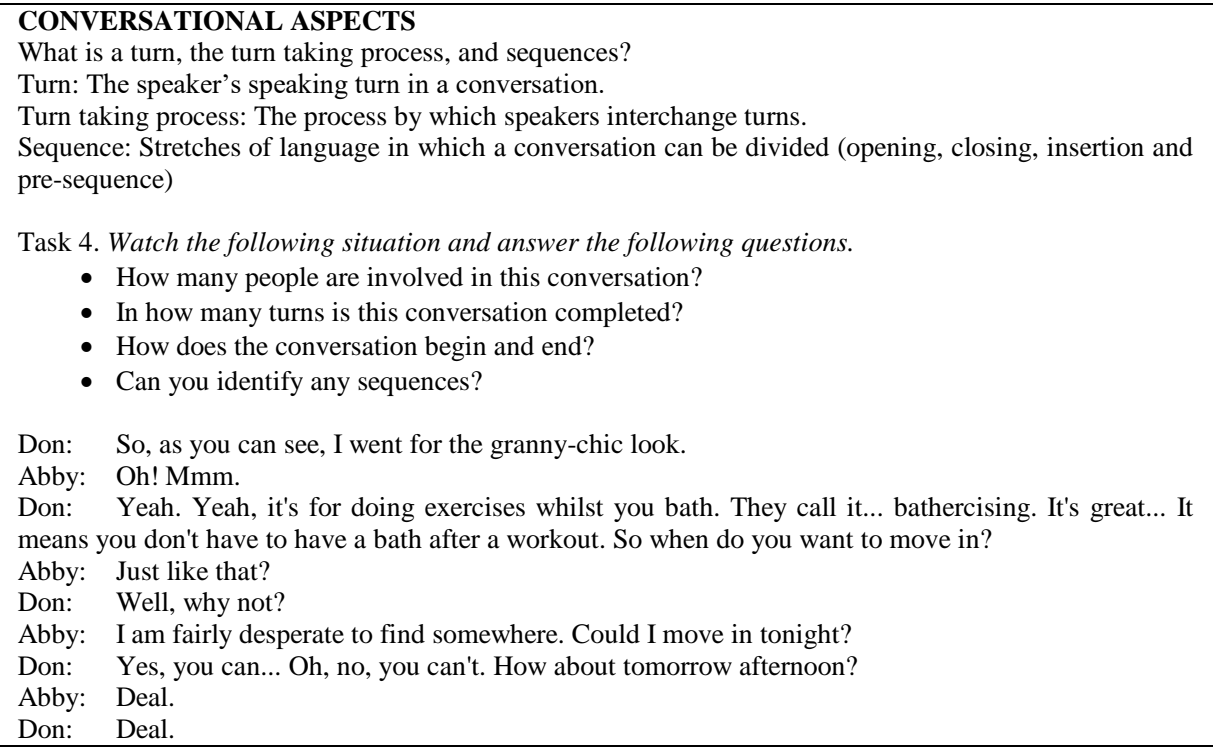

Figure 6

Task 4, conversational aspects identification.

Task 4 is devoted to the identification of turns, participants and conversational sequences. As seen above, a short definition of the concepts of conversation, turn, turntaking processes and sequences' typology are described to students. It is students' task to identify turns and sequences in the given conversation while discussing with the teacher and other learners. The teacher has to provide the students with the right answers and give extra examples if necessary.

Then, students are explicitly instructed on the SAs taxonomies as searched in the corpus by providing them with a short definition of the SA, a description of direct and indirect realizations, strategies and examples. Once learners have the ground knowledge for each SA individually, they will practice identification tasks (see below) while exposed to audiovisual fragments and transcripts.

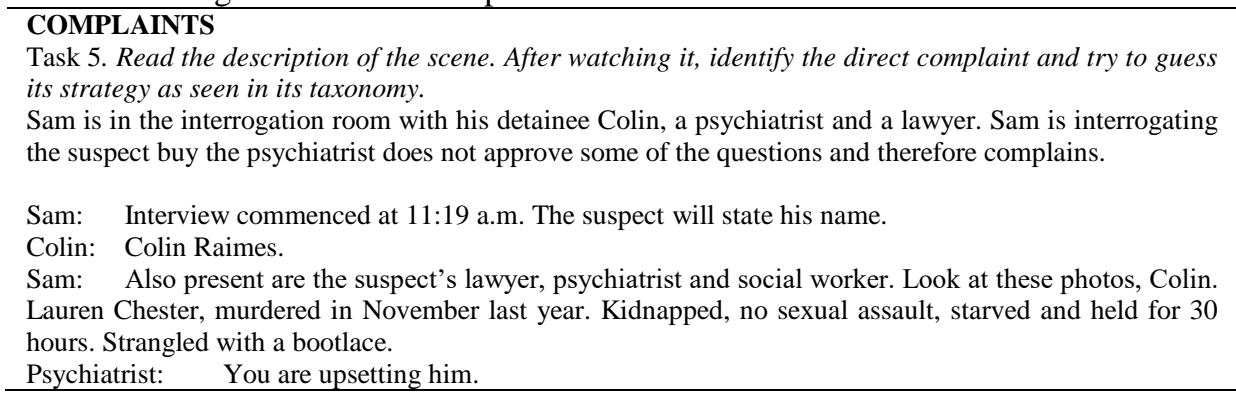
Figure 7

Task 5 individual SA identification. 


\section{$3^{\mathrm{RD}}$ Step: Integrating sociopragmatics and pragmalinguistics}

The last step is devoted to the identification of multiple SAs, conversational aspects and the assessment of conversational needs and interactants' linguistic production. The main aim is for students to reflect on their overall pragmatic knowledge as practiced throughout the previous steps. They will be provided with a sociopragmatic and pragmalinguistic aspects' questionnaire which consists of three different tasks below described. It is teachers' role to explain the tasks, supply students with multimodal input from the TV genres, i.e. audiovisual stimuli and transcripts, and provide guidance and support through the questionnaire completion process. Note that students may need access to their instructional materials.

The first task is aimed at the identification and classification of SAs, conversational sequences, and the understanding of participants' intended meaning. Having read the description of the situation, students have to watch the scene, identify the SAs and conversational sequences, note down their linguistic production, provide the strategy used, and guess the intended meaning of both speaker and hearer.

Task 1. After watching the conversation, answer the following questions. Read the transcript so as to clarify your answers.

What SAs can you identify?

What linguistic expressions are used by speakers?

Classify them according to its taxonomy

Is there any sequence?

What are speakers' intended meanings?

Figure 8

Task 1, pragmalinguistic aspects' identification.

The second multiple-choice task involves the assessment of sociopragmatic aspects. Based on the previous conversation, learners have to grade speakers' linguistic production as regards the sociopragmatic aspects of power, distance and imposition. Additionally, they need to evaluate the influence of the context and any salient features with reference to interactants overall behaviour (see below).

\begin{tabular}{ll}
\hline $\begin{array}{l}\text { Task 2. Regarding the following variables, choose the option that best defines speakers' } \\
\text { interaction. }\end{array}$ & Low moderate high \\
\hline Power & Close common distant \\
Distance & Low moderate high \\
Imposition & Low moderate high \\
Context influence & Feelings, image they want to project, attitude, emotional state, mood, \\
Speaker's behaviour & body language \\
\hline
\end{tabular}

Figure 9

Task 2, sociopragmatic aspects' evaluation.

The third task focuses on the assessment of interactants linguistic production from 4 (suitable) to 1 (unsuitable). The parameters students need to reflect on are the SA strategies used, the level of formality, directness or indirectness, the politeness effect on 
interactants' words, and pragmatic tone, which entails the appropriateness of the participants' linguistic production in the given interaction (see below).

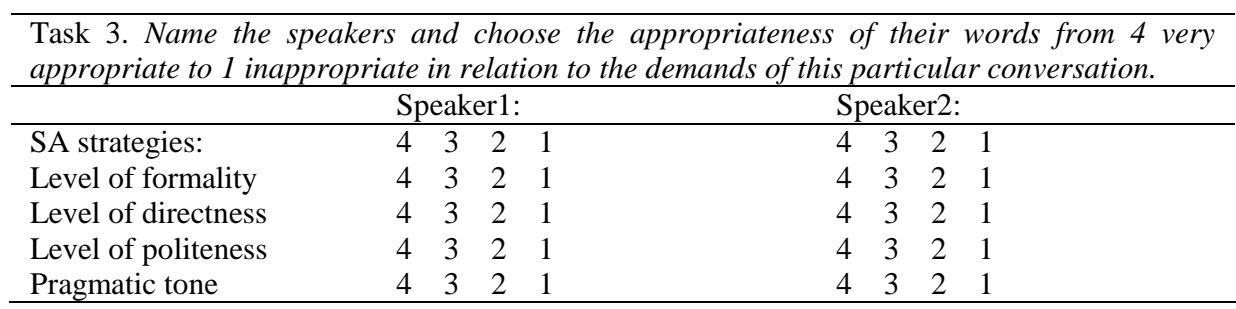

Figure 10

Task 3, overall linguistic production assessment.

Once students complete the questionnaire individually it is teachers' role to generate metapragmatic discussion by checking students' answers and the rationale behind. Meanwhile it is also necessary to provide them with explicit corrective feedback and accounting for more suitable answers if necessary.

The tasks proposed throughout the three stages of our pedagogical model can be modified taking into account EFL learners' curricular needs, learning stages and FL proficiency levels by means of selecting specific audiovisual interactions from the tagged corpus. It may also be highlighted that tasks can be repeatedly used for the study of as many SAs and strategies as suggested in the taxonomies. In relation to multimodal input provision, tasks can be adapted by modifying the audiovisual genres chosen, scenes length, dialectal varieties, and participants' pace of speech, to mention some. The use of transcripts so as to activate previous knowledge and allow constant access to the dialogues can also lessen the difficulty of the tasks. As a final remark, it would be advisable to use a maximum of two TV series, since students need to familiarize with the main plot and characters' motivations which may influence their linguistic behaviour; otherwise, they may not recall the required information so as to interpret and assess interactions.

\section{DISCUSSION}

This paper was aimed at the design of a teaching pragmatics proposal in the EFL learning context. With that objective in mind and taking into account FL learners' scarce access to the language being learnt, the compilation of a multimodal corpus was considered optimal so as to provide students with audiovisual rich and contextualized pragmatic input following CEFR (2018) conventions. Findings from the corpus are in agreement with previous research by Bonsignori (2018) and Furnis (2016) who developed their own corpora in search of contextualized language elements related to different ESP fields and the expression of routine formulas, respectively. Our corpus data differs from the previous studies since we have focused attention to the search of multiple SAs. Nevertheless, the data obtained has been used with FL teaching purposes in order to show students not only verbal elements but the interrelationship between semiotic (i.e. linguistic and paralinguistic resources) and different cultural and situational contexts which pragmatics entails. As regards the methodology, a corpus 
pragmatics approach similar to McAllister (2015) has been employed with the aim of identifying direct and indirect SAs examples in context and stablish form-function mapping.

Once the multimodal corpus was compiled, our teaching proposal has been designed to cover pragmalinguistic and sociopragmatic components of language following Ishihara and Cohen (2010) suggestions with reference to explicit instruction and instructional activities to foster pragmatic competence. The innovation resides in the provision and discussion of metapragmatic information (Glaser, 2013), a FonFormS (Ellis, 2002) in the last steps of instruction, the use of multimodal input centered on pragmatic aspects, and the performance of identification tasks and awareness-raising questionnaires for students to reflect on the connection between pragmalinguistic production and sociopragmatic aspects.

\section{CONCLUSION}

In this paper, the merging of corpus pragmatics methodologies and the provision of audiovisual input from a self-developed multimodal specialized ad-hoc corpus for the acquisition of pragmatic competence in the EFL learning context has been described. Due to the acknowledged lack of pragmatic input provision in the educational context, explicit instruction and the exposure to audiovisual reception activities and strategies, such as identification tasks and questionnaires may well help students' better noticing and understanding of conversational aspects, SAs' use and the possible constraints when using language. Likewise, the instructional model presented could potentially lead to an increase in pragmatic awareness. Thus, if awareness contributes to acquisition (Schmidt, 2012), instructing students on how to notice and interpret by themselves can be considered as a starting point for EFL pragmatics' acquisition to take place and as a step forward towards autonomy.

The pedagogical implications of the step-by-step teaching proposal presented in this article should be seen as a first stage to foster pragmatic competence since leaners' access to contextualised conversations in the format of multimodal input may aid at noticing the pragmatic features of flexibility, turntaking process, thematic development, coherence and cohesion, propositional precision and spoken fluency as described in the CEFR (2018). As our proposal does not provide students with opportunities for communicative practice since we are first concerned over its impact on awareness, future research should concentrate on the types of tasks and activities that better suit the instructional model described and learners' needs. Research into the effects of the pedagogical proposal on awareness is already underway.

\section{REFERENCES}

Abrams, Z. I. (2014). Using film to provide a context for teaching L2 pragmatics, System, 46, 55-64.

Adolphs, S. (2008). Corpus and Context: Investigating Pragmatic Functions in Spoken Discourse. Amsterdam and Philadelphia: John Benjamins. 
Alcón, E. (1997). Cognitive approaches for explaining the phenomena of second language acquisition and second language use in communication. Communication and Cognition 30, 7-28.

Alcón, E. \& Martínez-Flor, A. (2008). Investigating Pragmatics in FL Learning, Teaching and Testing. Bristol: Multilingual Matters.

Alcón, E. \& Guzmán Pitarch, J. (2010). The effect of instruction on learners’ pragmatic awareness: a focus on refusals. International Journal of English Studies, 10: 65-80.

Anthony, L. (2019). AntConc (Version 3.5.8) [Computer Software]. Tokyo, Japan: Waseda University. Available from https://www.laurenceanthony.net/software

Bardovi-Harlig, K. (2017). Acquisition of L2 pragmatics. In S. Loewen \& M. Sato (Eds.), The Routledge handbook of instructed second language acquisition, 224-245. New York: Routledge

Barron, A. (2003). Acquisition in interlanguage pragmatics. Learning how to do things with words in a study abroad context. Amsterdam: John Benjamins Publishing Company.

Boxer, D. (2010). Complaints, How to gripe and establish rapport. In A. Martínez-Flor and E. Usó-Juan (eds.), Speech act performance: theoretical, empirical and methodological issues, 163-178. Amsterdam: John Benjamins.

Bonsignori, V. (2018). Using films and TV series for ESP teaching: A multimodal perspective. System, 77, 58-69.

Brown, P. \& Levinson, S. C. (1987). Politeness: Some universals in language usage (Vol. 4). Cambridge University Press.

Camiciottoli, B. C. \& Campay-Cubilo, M. (2018). Introduction: The nexus of multimodality, multimodal literacy, and English language teaching in research and practice in higher education settings. System, 77, 1-9.

Campoy-Cubillo, M. C.; Belles-Fortuno, B.; \& Gea-Valor, M. L. (Eds.). (2010). Corpus-based approaches to English language teaching. A\&C Black.

Chang, Yuh-Fang. (2010). "I no say you say is boring": the development of pragmatic competence in L2 apology. Language Sciences 32, 408-424.

Council of Europe. (2018). Common European framework of reference for Languages: Learning, teaching, assessment. Companion volume with new descriptors. Cambridge: Cambridge University Press.

Crystal, D. (Ed.). (1997). The Cambridge encyclopedia of language (2nd ed.). NewYork: Cambridge University Press

DeCapua, A. (1998). The transfer of negative language speech into a second language: A basis for cultural stereotypes? Issues in Applied Linguistics 9(1), 21-35. 
Ellis, R. (2002). Does form-focused instruction affect the acquisition of implicit knowledge? A review of the research. Studies in Second Language Acquisition 24(2), 223-236.

Fernández-Guerra, A. (2008). Requests in TV Series and in Naturally Occurring Discourse: A Comparison. In E. Alcón (ed.), Learning How to Request in an Instructed Language Learning Context. Frankfurt: Peter Lang.

Flowerdew, J. \& Richardson, J. E. (Eds.). (2018). The Routledge handbook of critical discourse studies. Taylor \& Francis.

Furniss, E. (2016). Teaching pragmatics with corpus data: the development of a corpusreferred website for the instruction of routine formulas in Russian. In Yearbook of Corpus Linguistics and Pragmatics 2016, 129-152. Springer, Cham.

Glaser, K. (2013). The Neglected Combination: A Case for Explicit-Inductive Instruction in Teaching Pragmatics in ESL. TESL Canada Journal, 30(7), 150-163.

House, J. (1996). Developing pragmatic fluency in English as a FL: Routines and metapragmatic awareness. Studies in Second Language Acquisition, 18(2), 225-252.

Ishihara, N. \& Cohen, A. D. (2010). Teaching and learning pragmatics: Where language and culture meet. Harlow, UK: Pearson Education.

Jewitt, C. (2009). Routledge handbook of multimodal analysis. London: Routledge.

Kondo, S. (2010). Apologies. Raising learners' cross-cultural awareness. In A. Martínez-Flor and E. Usó-Juan (Eds.), Speech act performance. Theoretical, empirical and methodological issues, 145-162. Amsterdam: John Benjamins.

LoCastro, V. (2003). An introduction to pragmatics: Social action for language teachers. Ann Arbor, MI: The University of Michigan Press.

Martínez Flor, A. (2005). A theoretical review of the speech act of suggesting: Towards a taxonomy for its use in FLT. Revista alicantina de estudios ingleses, No. 18, 167-187.

Martínez-Flor, A. (2007). Analysing request modification devices in films: Implications for pragmatic learning in instructed FL context. In E. Alcón \& P. Safont (eds.) Intercultural language use and language learning, 245-280. Amsterdam. Springer.

Martínez-Flor, A. \& Alcón-Soler, E. (2007). Developing pragmatic awareness of suggestions in the EFL classroom: A focus on instructional effects. Canadian Journal of Applied Linguistics, 10(1), 47-76.

Martínez-Flor, A. \& Usó-Juan, E. (2010). Pragmatics and speech act performance. In A. Martínez-Flor and E. Usó-Juan (eds.), Speech act performance: theoretical, empirical and methodological issues, 3-20. Amsterdam: John Benjamins Publishing Company.

McAllister, P. G. (2015). Speech acts: a synchronic perspective. Corpus pragmatics: A handbook, 29-51. 
McEnery, T.; McEnery, A.; Xiao, R.; \& Tono, Y. (2006). Corpus-based language studies: An advanced resource book. Taylor \& Francis.

Murphy, B. \& Neu, J. (1996): My grade's too low: The speech act set of complaining, in: Susan M. Gass \& Joyce Neu (Ed.): Speech acts across cultures: Challenges to communication in second language. Berlin: Mouton de Gruyer, 191-216.

Olshtain, E. \& Weinbach, L. (1988). Giving and responding to complimentscharacterizing compliments in Israeli society. Hed Haulpan, 53, 35-39.

Olshtain E. \& Cohen, A. D. (1990). The learning of complex speech act behavior. TESL Canada journal, 7, 45-65.

Römer, U. (2011). Corpus research applications in second language teaching. Annual review of Applied Linguistics, 31, 205-225.

Rose, K. R. (2001). Compliments and compliment responses in films: Implications for pragmatics research and language teaching. International Review of Applied Linguistics, 39, 309-326.

Rose, K. R. \& Ng, Kwai-fun, C. (2001). Inductive and deductive teaching of compliments and compliment responses. In K. Rose \& G. Kasper (Eds.), Pragmatics in language teaching, 145-170. New York: Cambridge University Press.

Ross, S. J., \& Hong, Y. (2019). Mixed Methods in L2 Pragmatics Research. The Routledge handbook of second language acquisition and pragmatics, 212-225. Routledge.

Rühlemann, C. \& Aijmer, K. (2015). Corpus pragmatics: Laying the foundations. Corpus pragmatics: A handbook, 1-26.

Salazar, P.; Safont, M. P.; \& Codina, V. (2009). Refusal strategies: A proposal from a sociopragmatic approach. RAEL, Revista Electrónica de Lingüística Aplicada, 8, 139150.

Schmidt, R. (2012). Attention, awareness, and individual differences in language learning. In W. M. Chan, K. N. Chin, S. Bhatt \& I. Walker (Eds.), Perspectives on Individual Characteristics and FL Education, 27-50. Berlin: Walter de Gruyter.

Shih, Y, C. (2014). Communication strategies in a multimodal virtual communication context. System, 42, 34-47

Taguchi, N. \& Roever, C. (2017). Second language pragmatics. Oxford University Press.

Taguchi, N. (2019). Second language acquisition and pragmatics: An overview. In The Routledge handbook of second language acquisition and pragmatics, 1-14. Routledge.

Takahashi, S. (2010). Assessing learnability in second language pragmatics. In A. Trosborg (Ed.), Pragmatics across languages and cultures, 391-421. Berlin, Germany: Mouton de Gruyter. 
Tateyama, Y. (2019). Pragmatics in a language classroom. The Routledge handbook of second language acquisition and pragmatics, 400-412. Routledge.

Tatsuki, D. \& Kite, Y. (2006). Comparing Film Dialogue and Speech Act Data. Cited in Pragmatics Research. Teaching English through movies: ATEM journal, 11, 26-39.

Tatsuki, D. (2019). Instructional material development in L2 pragmatics. The Routledge handbook of second language acquisition and pragmatics, 322-337. Routledge.

Timmis, I. (2013). Corpora and materials: Towards a working relationship. Developing materials for language teaching, 461-474.

Tognini-Bonelli, E. (2001). Corpus linguistics at work (Vol. 6). Philadelphia, Amsterdam: John Benjamins.

Tognozzi, E. (2010). Teaching and evaluating language and culture through film. Italica, 69-91.

Tomlinson, B. \& Masuhara, H. (2018). The complete guide to the theory and practice of materials development for language learning. Hoboken, NJ: Wiley.

Trosborg, A. (1995). Interlanguage pragmatics. Requests, complaints and apologies. Berlin: Mouton de Gruyter.

Usó-Juan, E. (2010). A sociopragmatic approach. Speech act performance: Theoretical, empirical and methodological issues, 237-256.

Washburn, G. N. (2001). Using situation comedies for pragmatic language teaching and learning. TESOL Journal 10(4), 21-26.

Wayne, M. L. (2018). Netflix, Amazon, and branded television content in subscription video on-demand portals. Media, Culture \& Society, 40(5), 725-741.

Weinert, S. (2009). Implicit and explicit modes of learning: Similarities and differences from a developmental perspective. Linguistics 47, 241-71. 